\title{
Medical Errors in Greece: An Economic Analysis of Compensations Awarded by Civil Courts (2000-2009)
}

\author{
Marina Riga, Athanassios Vozikis, Yannis Pollalis \\ Department of Economic Science, University of Piraeus, Piraeus, Greece \\ Email: marina.riga@yahoo.com \\ Received 9 January 2014; revised 15 February 2014; accepted 23 February 2014 \\ Copyright (C) 2014 by authors and Scientific Research Publishing Inc. \\ This work is licensed under the Creative Commons Attribution International License (CC BY). \\ http://creativecommons.org/licenses/by/4.0/

(c) (i) Open Access

\section{Abstract}

Medical errors are reported with increased frequency both in Europe and in the United States of America and measures are put in place to deal with the problem. In Greece, more and more patients think that it is likely to experience a medical error during health care delivery and the organizations they can turn to if this happens are hardly enough and with meagre response. The consequences of medical errors are multiple and complex with significant financial implications. Nowadays there is an urgent need to resolve problems that refer to cost containment in the Greek Health System. Some research findings from the review of 128 compensations awarded by civil courts for the years 2000 to 2009 for medical errors in Greece are quite interesting. The mean compensation amounted to $€ 292,613$ representing $35.41 \%$ of claimed compensation. Only a small proportion of medical errors gain publicity as the majority of claims get settled out of court, covered by the insurance policy or the hospitals. The burden of the obvious and hidden cost affects not only the patient, his family and the hospital but also the whole of the society. This comes from our estimation that the level of compensation awarded by the civil courts for medical errors is remarkable high. Unfortunately only some estimates of the cost are possible due to the lack of statistical data. The creation of an independent oversight body for the review of medical errors and complaints nationwide as well as the modernization of the hospitals' monitoring systems is necessary in order to handle the medical error phenomenon. Above all, co-operation and trust between patients, health care professionals, hospital managers, medical boards and the government are essential to get to the root of the problem.

\section{Keywords}

Medical Errors; Adverse Events; Health Care System; Cost Containment; Cost-Effectiveness 


\section{Introduction}

Research shows that medical errors exist all over the world's health systems, compromising the patient safety and the quality of health care. The Institute of Medicine's (IOM) reports, "To Err Is Human: Building a Safer Health System” and “Crossing the Quality Chasm: A New Health System for the 21st Century”, underline the importance for health policy makers to taking into account the various implications of medical errors in patient safety and healthcare quality [1] [2]. Intensifying the above, the Euro barometer survey, which was released by the European Commission [3], found that almost half of those surveyed stated that patients should take into consideration that it is likely to be harmed by a medical error, during health care delivery.

In the present paper, we highlight and discuss the preliminary research findings about the amount of the compensations awarded in Greece, after the analysis of 128 cases coming from courts awards for the years 2000 to 2009. We also formulate recommendations in order to succeed in the reduction of the phenomenon of medical errors where the most important condition is the awareness of the problem among all stakeholders in the Greek health system.

In the following Sections 2 and 3, we indicate the theoretical aspects of adverse events and medical errors. In Sections 4 and 5, we present the research findings and draw conclusions respectively and finally we propose additional policies of reducing the number of patients harmed by medical errors.

\section{Theoretical Aspects of Adverse Events and Medical Errors}

In the literature of health care quality, we can find various definitions of medical errors. The World Health Organization (WHO) in the "Collaborating Centers for International Drug Monitoring” and the IOM in the "To Err is Human", clarify the definition of the adverse event and the medical error [1] [4]:

"An error is defined as the failure of a planned action to be completed as intended or the use of a wrong plan to achieve an aim."

Moreover, in the literature we can find the expanded IOM definition, reported by QuIC [5]: “An error is defined as the failure of a planned action to be completed as intended or the use of a wrong plan to achieve an aim. Errors can include problems in practice, products, procedures, and systems."

In contrast with the above definitions, various classifications of medical errors can be found, referring not only in the treatment but also in diagnosis and prevention stages of health care delivery [1] [6]-[8]. Also, the medical errors can be classified based on their severity, ranging from those that don't cause any harm to those with severe harm. Categories A, B, C and D describe errors that do not cause harm, while categories E, F, G, H, and I of the NCC MERP Index describe errors that do cause harm.

Though medical errors are likely to occur, as health care personnel are human beings, many researchers believe that the main causes of medical errors refer to systemic failures. Relying on this assumption, medical errors happen, in general, by the complexity and time-pressured of health systems and less by the negligence of health care personnel. Donald M. Berwick, president of the Institute for Health Care Improvement and experts in the American Medical Association [9] espouse this point of view, as they recommend the simplification, more standardization in the health care system and the motivation of health care professionals to report the medical errors, aiming to enhanced patient safety and the improvement of health care quality.

\section{Medical Errors: Figures and Cost}

As above mentioned, the phenomenon of medical errors is common to the health systems all over the world. In the United States, the figures of medical errors are very high and half of the adverse events occurring because of medical errors that could be prevented, resulting in the death of thousands. On the other hand, medical errors, except of physical harm, cost a lot of money in the health system of the United States, as Table 1 shows [1] [10]-[19].

In Europe, the landscape isn't different, as the research indicates a significant proportion of patients are harmed by a medical error during a hospital stay [20]-[22]. In Greece, there isn't a central national authority to report cases of medical errors. However, recent findings show that about 20 to 30 patients die every day and other 200 are harmed because of medical errors that could be prevented [23].

\section{Research Findings}

The scope of this paper is to the economic analysis of 128 compensations awarded by civil courts for the years 
Table 1. Estimated annual mortality and economic cost of medical intervention.

\begin{tabular}{ccc}
\hline Condition & Deaths & Cost \\
\hline Adverse Drug Reactions & 106,000 & $\$ 12$ billion \\
Medical Error & 98,000 & $\$ 2$ billion \\
Bedsores & 115,000 & $\$ 55$ billion \\
Infection & 88,000 & $\$ 5$ billion \\
Malnutrition & 108,800 & ---------- \\
Outpatients & 199,000 & $\$ 77$ billion \\
Unnecessary Procedures & 37,136 & $\$ 122$ billion \\
Surgery-Related & $\mathbf{3 2 , 0 0 0}$ & $\$ 9$ billion \\
Total & $\mathbf{7 8 3 , 9 3 6}$ & $\mathbf{\$ 2 8 2}$ billion \\
\hline
\end{tabular}

Source: Null et al., 2007.

2000 to 2009 for medical errors in Greece. For every case, we recorded the year of the recourse or the award publication, the legal status of the health care organization, the medical specialty, the type of medical error, the severity of the adverse event and the amount awarded.

In Greece, contrary to other countries, the assessment of the total financial burden is difficult to be accurately approached due to the lack of data from an organized information system. Thus, the implementation of a system with the ability to recognize, report and analyze cases of adverse events and medical errors following the international standards, is crucial.

Our research pointed out that in Greece, the amount and the level of compensation awarded by civil courts for medical errors in Greece is worryingly high. In addition, the frequency and the amount of mean compensation have been dramatically increased in the late years (Graphs 1 and 2, respectively).

The most injurious specialties (either in terms of frequency involvement or of the mean compensation amount) are General Surgeons, Obstetricians-Gynecologists, Anesthesiologists and Neurosurgeons (Graphs 3 and 4).

The highest mean compensation awarded to the severity of adverse events Category I: Patient death and to the Category G: Permanent patient harm. It is remarkable that the awarded mean compensations for the Category $H$ : Intervention required to sustain life is lower than those to adverse events category with minor severity (Category F: Temporary harm to the patient and required initial or prolonged hospitalization) (Graph 5).

The highest mean compensation awarded to the public hospitals due to a big number of cases extracted by Administrative Courts (Graph 6).

\section{Discussion-Policy Proposals}

Our research shows that medical errors really exist in the Greek health care system, as in every health care system, worldwide. In a relative research in Austria, in a sample of 14,179 hospitalized patients, adverse events were identified in the $16.6 \%$ of them, of which $13.7 \%$ impacted to permanent patient harm, $4.9 \%$ related to death and 51\% could be prevented [24].

Our findings show that the allocation in the categories I and G which referred to patient death and to permanent patient harm respectively, is in accordance with a study for medication errors which took place in New York [25]. A study in 9,758 medical claims, mentions that 32\% refer to death and 15\% to significant permanent injury [26]. Furthermore, another international research indicates that the cost of adverse events with temporary harm reached to $\$ 324$ million [27]. Other study shows that 5,000 deaths by medical errors in the USA are recorded every year [28].

Based on our findings, the specialties of General Surgery, Obstetrics-Gynecology, Anesthesiology and Neurosurgery appear to have increased involvement in medical errors, which are consistent with the findings of other surveys [29] [30]. Moreover, a study by the Ministry of Health of USA concludes that the specialties of General Surgery and Obstetrics-Gynecology are the top two specialties which are burdened with medical malprac- 


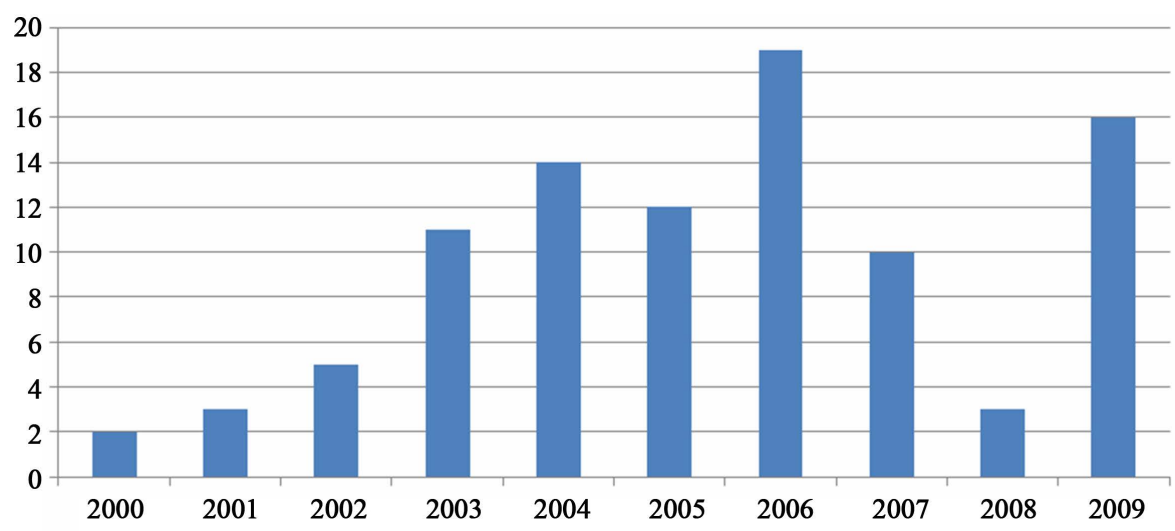

Graph 1. Number of court decisions per year (2000-2009).

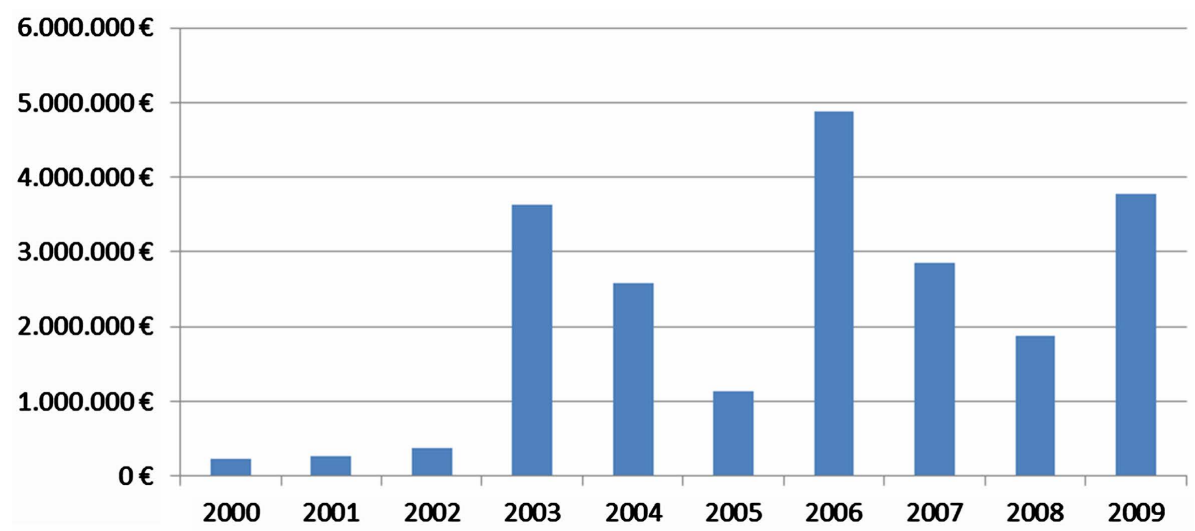

Graph 2. Mean compensation amount per year (2000-2009).

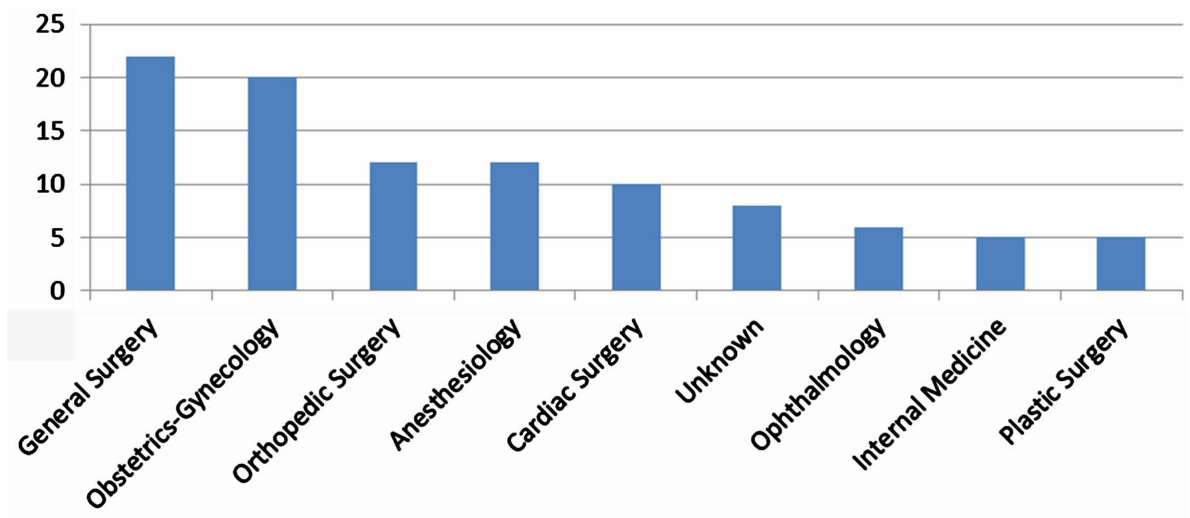

Graph 3. Frequency of compensation awarded per specialty during the years 2000-2009 (>5 awards).

tice [31]. These findings confirm previous similar research pointing out that the specialties of Vascular Surgery, Obstetrics-Gynecology, Cardiology and Neurosurgery had more chances for causing an adverse event [32]. Another study shows that in a sample of 465 adverse events, 127 are due to medical malpractice where $61 \%$ relate with surgical procedure injuries, $12 \%$ refer to drug injuries and $11 \%$ deal with nonsurgical procedure [33].

Furthermore, medical errors cause substantial economic burden to the patients and to their relatives, to the health system and to the insurance industry and raise the issue of medical professional liability to the doctors involved. The interest for studying medical errors in all developed countries is due to the impact on the quality 


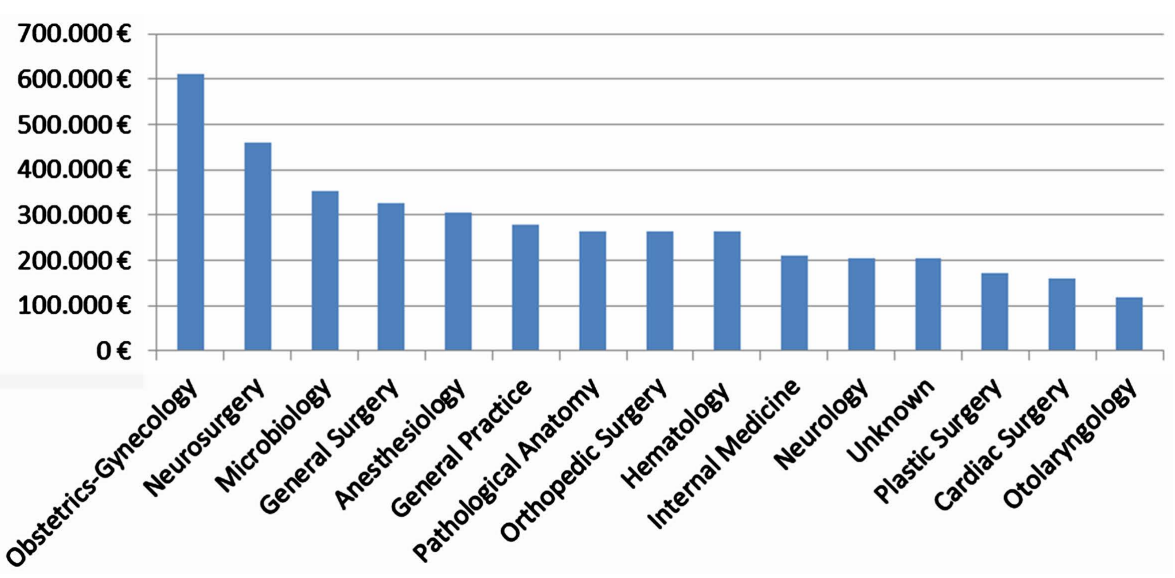

Graph 4. Mean compensation for various specialties (>€100000.00).

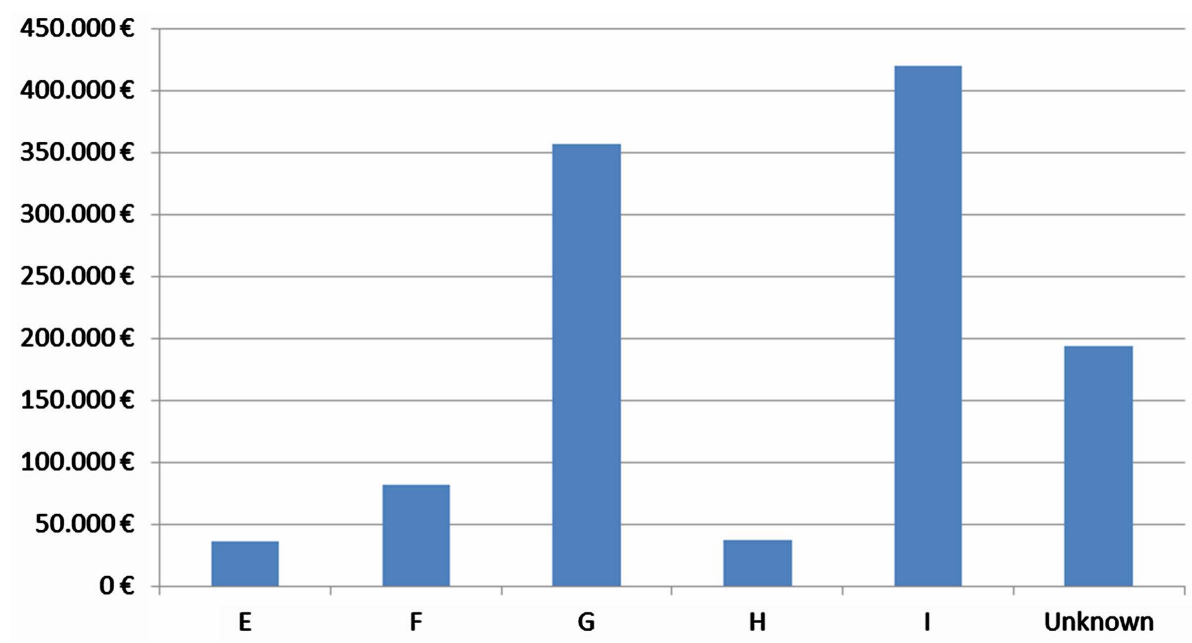

Graph 5. Mean compensation for adverse events severity categories.

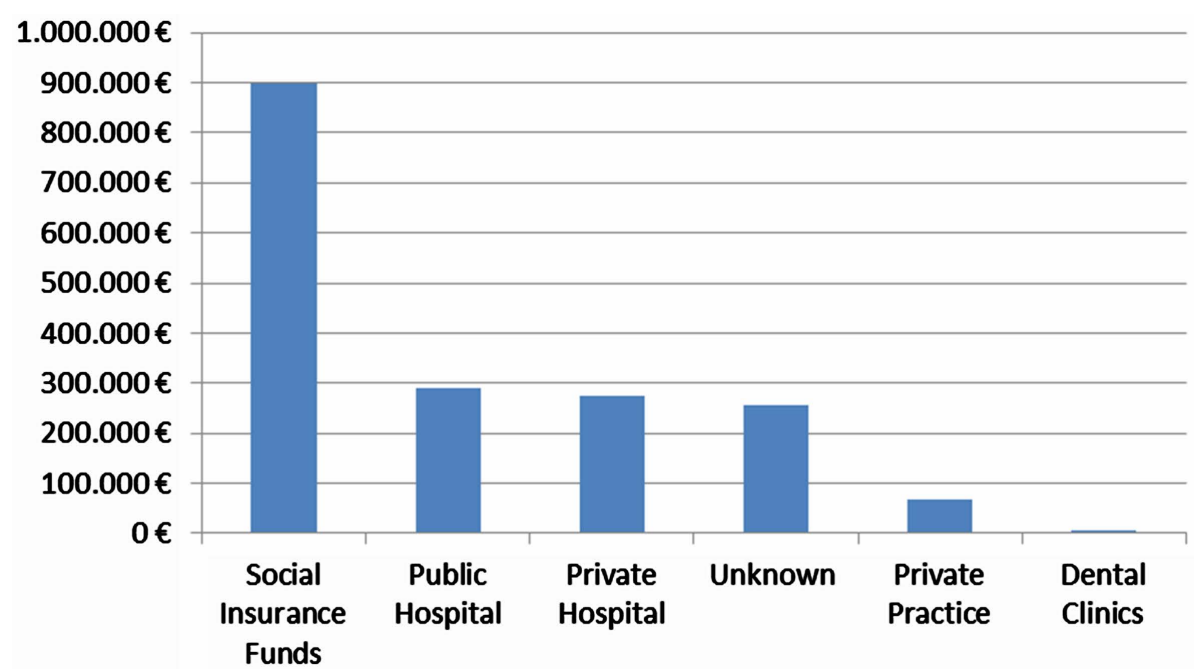

Graph 6. Mean compensation by type of heath care provider.

of health services and also to a number of legal actions for damages from the patients where the court decision is condemnatory for the doctors many times [34]. 
In an American study, 27\% of adverse events were the result of medical malpractice [35] and an extended study based on the previous, with a sample of 465 medical records, showed that $\$ 1,791,358$ were related with medical injuries and for 127 of cases due to negligence, the American health system was burdened with $\$ 905,719$ [33]. Another research indicates that medical injuries cost $\$ 6.3$ million of which $\$ 1.5$ million were due to medical error [36].

On the basis of our research findings, we note that the mean compensation for the specialty Obstetrics-Gynecology scaled up to $€ 612,561$. This is consistent with the findings of a study which mentions that both the Emergency Department and the specialty of Obstetrics-Gynecology cover 28\% of all financial demands or \$2 million [37]. Other recent research from Utah shows that 58\% of adverse events are surgical, of which $25 \%$ refer to foreign objects retained after surgery, especially in surgeries of Obstetrics-Gynecology. The remaining cases deal with nonsurgical events like healthcare management and hospital environment [38].

There is no doubt that the root cause of medical errors is due to a systemic approach which should take into account the contribution of health system structure and organization [39] [40]. Specifically, the systemic factors are mainly due to staff shortage (quantitative and qualitative approach), to unsafe working environment, to the severity of the patients admitted, to the increased workload and to the professional burnout. The inadequate staffing of healthcare system and their insufficient education are among the most important parameters that may compromise the patient safety and the quality health care provision [41]-[43].

For achieving a high level of health care quality and patient safety in health system, it is essential to take strategically designed actions to reduce medical errors, involving the health care professionals and using Information Technology for detecting, reporting and analyzing the adverse events and medical errors [44]-[48].

In Greece, a similar system has already been developed and its pilot implementation is running out in a public Intensive Care Unit (ICU) and so far it is considered crucial to the efforts for improving the quality of healthcare services provision and patient safety [49] [50]. In the USA, a health information system that reports adverse events was developed, accompanied by a root-cause analysis module [51] [52].

It is obvious that the health policy makers should seriously take into consideration the medical error phenomenon and act in the direction of reducing these incidents, primarily due to the high cost associated with them [21].

\section{Acknowledgements}

This research has been co-financed by the European Union (European Social Fund-ESF) and Greek national funds through the Operational Program "Education and Lifelong Learning" of the National Strategic Reference Framework (NSRF)—Research Funding Program: Heracleitus II. Investing in knowledge society through the European Social Fund.

\section{References}

[1] Institute of Medicine [IOM] (1999) To Err Is Human: Building a Safer Health System. National Academy Press, Washington DC.

[2] Institute of Medicine [IOM] (2001) Crossing the Quality Chasm: A New Health System for the 21st Century. National Academy Press, Washington DC.

[3] European Opinion Research Group (2010) Patient Safety and Quality of Healthcare-Full Report Special Euro Barometer 327/72.2. Directorate-General for Health and Consumers, European Commission, Belgium.

[4] World Health Organization [WHO] (1984) Publication DEM/NC/84.153(E). WHO, Geneva.

[5] Quality Interagency Coordination Task Force [QuIC] (2000) Doing What Counts for Patient Safety: Federal Actions to Reduce Medical Errors and Their Impact, Report to the President. http://www.quic.gov/report/mederr4.htm\#evidence

[6] National Coordinating Council on Medication Error Reporting and Prevention [NCC MERP] (1998) Taxonomy of Medication Errors.

[7] Joint Commission on Accreditation of Healthcare Organizations [JCAHO] (2011) Sentinel Event Policy and Procedures. http://www.jointcommission.org/Sentinel_Event_Policy_and_Procedures/

[8] Leape, L.L. (1993) Preventing Medical Injury. QRB Quality. Review Bulletin, 19, 144-149.

[9] VHA/Institute for Healthcare Improvement [VHA/IHI] (2002) IHI Intensive Care Unit (ICU) Adverse Event Trigger Tool IDICU Project, v.1. http://www.ihi.org/knowledge/Pages/Tools/ICUAdverseEventTriggerTool.aspx

[10] Null, G., Dean, C., Feldman, M., Rasio, D. and Smith, D. (2007) Death by Medicine. Life Extension Foundation. 
[11] Lazarou, J., Pomeranz, B.H. and Corey, P.N. (1998) Incidence of Adverse Drug Reactions in Hospitalized Patients: A Meta-Analysis of Prospective Studies. JAMA, 279, 1200-1205. http://dx.doi.org/10.1001/jama.279.15.1200

[12] Xakellis, G.C., Frantz, R. and Lewis, A. (1995) Cost of Pressure Ulcer Prevention in Long-Term Care. Journal of the American Geriatrics Society, 43, 496-501.

[13] Barczak, C.A., Barnett, R.I., Childs, E.J. and Bosley, L.M. (1997) Fourth National Pressure Ulcer Prevalence Survey. Advances in Wound Care, 10, 18-26.

[14] Weinstein, R.A. (1998) Nosocomial Infection Update. Emerging Infectious Diseases, 4, 416-420. http://dx.doi.org/10.3201/eid0403.980320

[15] Centers for Disease Control and Prevention [CDC] (2000) Morbidity and Mortality Weekly Report [MMWR]. Fourth Decennial International Conference on Nosocomial and Healthcare-Associated Infections, 25 February 2000, 49, 138.

[16] Burger, S.G., Kayser-Jones, J. and Bell, J.P. (2000) Malnutrition and Dehydration in Nursing Homes: Key Issues in Prevention and Treatment. National Citizens' Coalition for Nursing Home Reform.

[17] Starfield, B. (2000) Is US Health Really the Best in the World? JAMA, 284, 483-485. http://dx.doi.org/10.1001/jama.284.4.483

[18] Agency for Healthcare Research and Quality (2003) Healthcare Cost and Utilization Project. Rockville. http://www.ahrq.gov/data/hcup/hcupnet.htm.

[19] Tunis, S.R. and Gelband, H. (1994) Health Care Technology in the United States. Health Policy, 30, 335-396. http://dx.doi.org/10.1016/0168-8510(94)00692-8

[20] GeneralCologneRe (2002) Insurance Issues in Europe: Impending Changes in the European Health Care Sector and the Effect on Risk Management and Malpractice Insurance. https://www.facworld.com/WebLib.NSF/Object/healthcare_and_medmal_europe.pdf/\$File/healthcare_and_medmal_e urope.pdf

[21] National Coalition on Health Care and the Institute for Healthcare Improvement (2000) Reducing Medical Errors and Improving Patient Safety Success Stories from the Front Lines of Medicine. Monograph in Accelerating Change Today (A.C.T.) foe America's Health.

[22] Thomas, E.J., Studdert, D.M., Runciman, W.B., Webb, R.K., Sexton, E.J., Wilson, R.M., et al. (2000) A Comparison of Iatrogenic Injury Studies in Australia and the USA. I: Context, Methods, Casemix, Population, Patient and Hospital Characteristics. International Journal for Quality in Health Care, 12, 371-378. http://dx.doi.org/10.1093/intqhc/12.5.371

[23] Vozikis, A. and Riga, M. (2008) Medical Errors in Greece: The Economic Perspective through the Awards of Administrative Courts. Journal of Society, Economy and Health, 2, 423-437.

[24] Wilson, R.M., Runciman, W.B., Gibberd, R.W., Harrison, B.T., Newby, L. and Hamilton, J.D. (1995) The Quality in Australian Health Care Study. Medical Journal of Australia, 163, 458-471.

[25] Duthie, E., Favreau, B., Ruperto, A., Mannion, J., Flink, E. and Leslie, R. (2005) Quantitative and Qualitative Analysis of Medication Errors: The New York Experience. Advances in Patient Safety, 1, 131-144.

[26] Lincoln, T. (2012) Malpractice Payments Sunk to Record Low in 2011. Public Citizen’s Congress Watch, Washington DC. http://www.citizen.org/documents/npdb-report-2012.pdf

[27] Center for Justice \& Democracy (2010) Recent Medical Malpractice Studies: Alarming and Costly Medical Errors; Major Errors Go Unreported; Lawsuits Continue to Drop. http://www.msllegal.com/downloads/Center-Justice-Democracy-Medical-Malpractice-Study-December2010.pdf

[28] Hayward, R.A. and Hofer, T.P. (2001) Estimating Hospital Deaths Due to Medical Errors. JAMA, 286, 415-420. http://dx.doi.org/10.1001/jama.286.4.415

[29] Studdert, D.M., Mello, M.M. and Brennan, T.A. (2004) Medical Malpractice. New England Journal of Medicine, 350, 283-292. http://dx.doi.org/10.1056/NEJMhpr035470

[30] Bates, D.W., Cullen, D.J., Laird, N., Petersen, L.A., Small, S.D., Servi, D., et al. (1995) Incidence of Adverse Drug Events and Potential Adverse Drug Events. Implications for Prevention. JAMA ADE Prevention Study Group, 274, 29-34.

[31] US Department of Health and Human Services (2002) Confronting the New Health Care Crisis: Improving Health Care Quality and Lowering Costs by Fixing Our Medical Liability System. Office of the Assistant Secretary for Planning and Evaluation, Washington DC.

[32] US Congress, Office of Technology Assessment (1994) Defensive Medicine and Medical Malpractice. US Government Printing Office, Washington DC.

[33] Mello, M., Studdert, D., Thomas, E., Yoon, C. and Brennan, T. (2007) Who Pays for Medical Errors? An Analysis of Adverse Event Costs, the Medical Liability System and Incentives for Patient Safety Improvement. Journal of Empiri- 
cal Legal Studies, 4, 835-860. http://dx.doi.org/10.1111/j.1740-1461.2007.00108.x

[34] Zhan, C. and Miller, M.R. (2003) Excess Length of Stay, Charges, and Mortality Attributable to Medical Injuries during Hospitalization. JAMA, 290, 1868-1874. http://dx.doi.org/10.1001/jama.290.14.1868

[35] Studdert, D.M., Thomas, E.J., Burstin, H.R., et al. (2000) Negligent Care and Malpractice Claiming Behavior in Utah and Colorado. Medical Care, 38, 250. http://dx.doi.org/10.1097/00005650-200003000-00002

[36] Clark, C. (2010) Top 10 Most Costly, Frequent Medical Errors. Health Leaders Media. http://www.healthleadersmedia.com/industry_survey

[37] Larcher, G. and Dulberger, T. (2008) Trends in Medical Malpractice. Patients versus Profits. CAS Spring Meeting, Quebec, 15-18 June 2008.

[38] Utah Department of Health (2010) Utah Sentinel Events Data Report, Identifying Opportunities for Improvement. Health Insight and Utah Hospitals \& Health Systems Association. http://health.utah.gov/psi/

[39] Kelly, D. (2006) Applying Quality Management in Healthcare: A Systems Approach. 2nd Edition, Health Administration Press, AUPHA Press, Washington DC.

[40] Council of Europe (2006) Recommendation Rec7 of the Committee of Ministers to Member States on Management of Patient Safety and Prevention of Adverse Events in Health Care. 965th Meeting of the Ministers' Deputies, Committee of Ministers, 24 May 2006.

[41] Konver, C. and Gergen, P.J. (1998) Nurse Staffing Levels and Adverse Events Following Surgery in US Hospitals. Image: Journal of Nursing Scholarship, 30, 315-321. http://dx.doi.org/10.1111/j.1547-5069.1998.tb01326.X

[42] Aiken, L.H., Clarke, S.P., Sloane, D.M., Sochalski, J. and Silber, J.H. (2002) Hospital Nurses Staffing and Patient Mortality, Nurse Burnout, and Job Dissatisfaction. JAMA, 288, 1987-1993. http://dx.doi.org/10.1001/jama.288.16.1987

[43] Mitsis, D., Kelesi, M. and Kapadohos, T. (2012) Factors Which Affect the Occurrence of Nursing Errors in Medication Administration and the Errors’ Management. Rostrum of Asclepius, 11, 293-312.

[44] National Quality Forum (NQF) (2010) Safe Practices for Better Healthcare-2010 Update: A Consensus Report. NQF, Washington DC.

[45] House of Commons (2009) Patient Safety: Sixth Report of Session 2008-09. Vol. 1, Health Committee.

[46] European Commission (2008) Report on the Open Consultation on Patient Safety in the European Union. D.G. for Health and Consumers, Brussels.

[47] US Department of Health and Human Services (2011) National Strategy for Quality Improvement in Health Care: Report to Congress. US Department of Health and Human Services, Washington DC.

[48] Gregory, D. (2008) Adverse Health Event Management: International and Canadian Practices. A Background Document Prepared for the Task Force on Adverse Health Events. Ottawa.

[49] Vozikis, A., Pollalis, Y., Riga, M., Magina, N., Stoufis, N. and Teneketzi, Z. (2012) System for the Detection, Recording and Analysis of Adverse Events: Implementation in Intensive Care Units (ICU-MERIS). Archives of Hellenic Medicine, 29, 345-353.

[50] Vozikis, A. (2009) Information Management of Medical Errors in Greece: The MERIS Proposal. International Journal of Information Management, 29, 15-26. http://dx.doi.org/10.1016/j.ijinfomgt.2008.04.012

[51] Leapfrog Group (2006) The Leapfrog Group Issues Call for Hospitals to Commit to New Policy on Health Care "Never Events". http://www.leapfroggroup.org/media/file/Never Events release FINAL.pdf

[52] Consumers Union (2009) To Err Is Human-To Delay Is Deadly. Ten Years Later, a Million Lives Lost, Billions of Dollars Wasted. http://www.safepatientproject.org 